\title{
Diálogos em ação: \\ o cinema falado e as tensões na \\ construção da nacionalidade \\ brasileira (1920-1930)
}

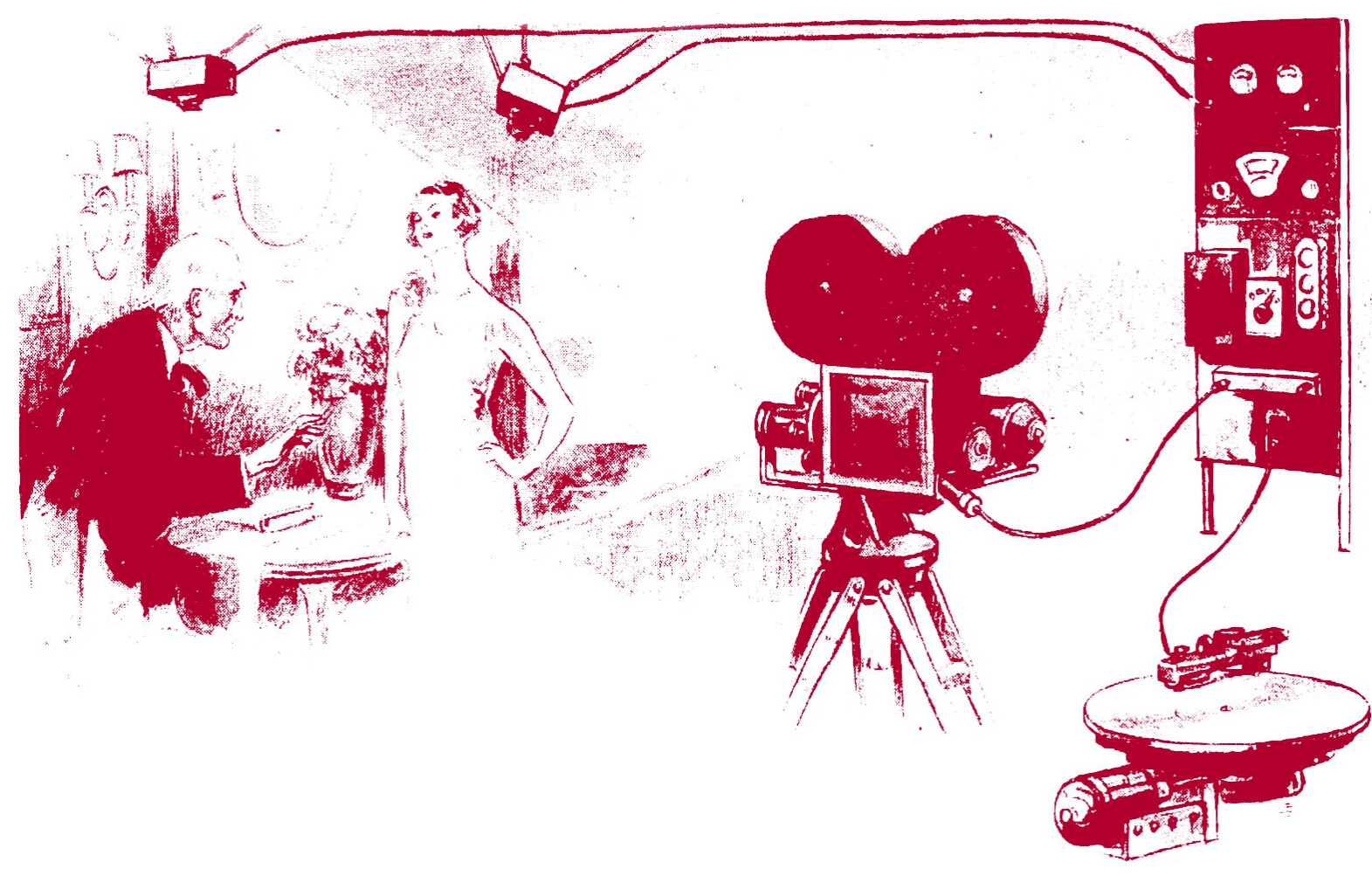

Imagem da revista Cinearte,

\section{Carla Miucci Ferraresi de Barros}

Doutora em História Social pela Universidade de São Paulo (USP). Professora do Instituto de História e do Programa de Pós-graduação em História da Universidade Federal de Uberlândia (UFU). Coorganizadora, entre outros livros, de História em projetos. Velhos mundos e mundos novos: encontros e desencontros - do século XVI ao XVIII. $7^{0}$ ano. 2. ed. São Paulo: Ática, 2011. carla.miucci@gmail.com 


\section{Diálogos em ação: o cinema falado e as tensões na construção da nacionalidade brasileira (1920-1930)}

Dialogues in action: the talking movie and tensions in the construction of Brazilian nationality (1920-1930)

\section{Carla Miucci Ferraresi de Barros}

\section{RESUMO}

Considerando o processo que deu voz às estrelas do écran, numa operação que tornou capaz a fixação da fala, da trilha musical e dos ruídos gravados junto à película, o artigo busca refletir, a partir da análise de publicações em revistas especializadas veiculadas pela imprensa nas décadas de 1920 e 1930, como a chegada do cinema falado no Brasil - especificamente em São Paulo e no Rio de Janeiro - não só impactou a maneira de fazer, distribuir e consumir os filmes, como participou de um intenso debate entre diferentes perspectivas acerca do tenso e contraditório processo de construção de uma moderna nacionalidade brasileira.

PALAVRAS-CHAVE: cinema-falado; modernidade; nacionalidade.

\begin{abstract}
Considering the process that gave voice to the screen stars in a operation that made speach fixation, sound tracks, and recorded noises present and adding another layer to the film, this article seeks to reflect what the printed press of the 20's and 30's published about the arrival of spoken cinema in Brazil in niched film making magazines - mainly, in São Paulo and Rio - and how it impacted not only in the movie making, writting, distribuiting and consumming, but also, took part in the differents perspectives given the contradictory and tense scenery of the build up process of the Brazilian nationality.
\end{abstract}

KEYWORDS: talking-movie; modernit;, nationality.

O cinema falado, desde que se organize entre nós, será um vastíssimo campo aberto à uma padronização da arte brasileira, a uma arte mais collectiva, mais uniforme, não se falando dos enormes benefícios que virá trazer à língua portuguesa falada no Brasil, com a disseminação, por todo o paiz, da melhor linguagem dentro do nosso variado dialect.

Humberto Mauro, $1932 .^{1}$

A sincronização do som à imagem em movimento, no cinema, dá-se no bojo de um processo marcado pelo desenvolvimento técnico e por mudanças nas percepções e sensibilidades, que culminaram, no final dos anos de 1920, em dois sistemas: o que permitia a sincronização a partir da gravação do som em disco, através de circuito de válvulas chamado Vitaphone; e o sistema óptico que possibilitava a gravação do som diretamente na película, chamado

\footnotetext{
${ }^{1}$ MAURO, Humberto. Cinema falado no Brasil. Cinearte, v. 11, Rio de Janeiro, 1932, p. V.
} 
Movietone. Essas inovações prometiam alterar significativamente a maneira de fazer e de consumir os filmes, afetando não só a produção dos grandes estúdios de Hollywood como também os mercados exibidores, dentro e fora dos EUA.

No Brasil, onde a ocupação do mercado cinematográfico pelas produções hollywoodianas vinha num crescendo desde o final da Primeira Guerra, com acentuada elevação a partir de 1920 e alcançando $90 \%$ em 19272, a chegada do cinema falado impactou diretamente o mercado nacional e suscitou discussões sobre seus limites éticos, estéticos e morais, protagonizadas por parte da imprensa escrita da época.

Periódicos veiculados nas capitais como São Paulo e Rio de Janeiro, como as revistas Cinearte (RJ), Para Todos (RJ), Revista Feminina (SP) e colunas em jornais de grande circulação e alta tiragem, como a "Cinematógrapho", assinada pelo literato Guilherme de Almeida no jornal O Estado de S. Paulo, traziam artigos e publicavam cartas dos leitores em que o cinema falado era pauta. Mas, o que se falava sobre o cinema falado? O que estes periódicos veiculavam sobre o assunto? Quais as opiniões publicadas nas colunas sobre os talkies? Essas indagações nos levam a outras, que dizem respeito ao papel que o cinema falado, especialmente o hollywoodiano, teve durante o tenso, contraditório e multifário processo de construção de um projeto civilizador e modernizador para o país.

\section{A modernidade conservadora e a voz do cinema em disputa}

Se havia um certo consenso nos discursos veiculados por parte da grande imprensa escrita da década de 1920, acerca da necessidade do país civilizar-se, por outro, a própria noção de civilização não era unânime. Apesar do discurso das elites governantes da Primeira República estar calcado no positivismo e na crença evolucionista do desenvolvimento das sociedades, baseada nos ideais iluministas de racionalidade e progresso, associando os conceitos de civilização e modernização, havia nuances que borravam as fronteiras dessa definição.

Ainda que o discurso civilizador com o qual parcela da elite nacional se identificava apresentasse, à primeira vista, um tom homogêneo e normativo que se contrapunha à diversidade das práticas cotidianas, ele não era uníssono: ora os novos aparatos e ritmos trazidos pela modernidade eram reverenciados como representantes do tão afamado progresso, ora eram renegados em nome de aspectos do que se entendia ser a cultura tradicional.

Concomitante à popularização dos novos equipamentos trazidos pelo processo de modernização, como o próprio cinema, parcelas da elite paulistana representadas pelo discurso de certos poetas, literatos e jornalistas, buscavam resgatar uma tradição idealizada ligada à busca de uma identidade na-

\footnotetext{
2 Ver SELONK, Aletéia P. de Almeida. Distribuição cinematográfica no Brasil e suas repercussões políticas e sociais - um estudo comparado da distribuição da cinematografia nacional e estrangeira. Disponível em $<$ https://www.ancine.gov.br/media/SAM/AnosAnteriores/teses_monografias/SelonkAleteiaDistribuicao.pdf >. Acesso em 10 abr. 2020.
} 
cional, que atravessou boa parte da nossa literatura desde a independência. ${ }^{3}$ Dentre esses nomes, Guilherme de Almeida figura como um autor influente, cujos escritos ganharam grande circulação por meio de sua coluna diária " $\mathrm{Ci}$ nematógrapho", veiculada pelo jornal O Estado de S. Paulo.

Querido leitor,

Hoje, dia de São João, você irá de noite, ao cinema. Irá. Antigamente, você iria a uma festa familiar com mocinhas, doces e fogos, numa chácara ou fazenda. Você mudou. As coisas mudaram. Entretanto, existem pessoas que você chama de atrasadoras, velhas de espírito, fora de moda, porque fiéis à tradição, que ainda gostam de soltar bicha, comer cuscuz e tirar a sorte. Olhe um pouco para cima: veja só quantas luzes pequeninas, amarelas, arrastadas pelo céu frio. São balões que vão levar às estrelas trêmulas, um pouco de calor - esse bom, antigo calor que sobra naquelas almas e que falta na sua, leitor moderno!!4

Para o autor, o leitor moderno perdera a sensibilidade, já que não conseguia mais apreciar as práticas tradicionais. Seu discurso satiriza as pessoas "modernas" frequentadoras do cinema, que preteriam as festas e os costumes "tradicionais" pelas sessões na sala escura. O autor constrói uma oposição entre o homem moderno e aquele que apresentaria um senso de tradição. Numa perspectiva romântica, Guilherme de Almeida acusa o homem moderno de ter perdido o "calor" contido nos costumes tradicionais de outrora, os quais a frieza da máquina de projetar, a velocidade das imagens em movimento na tela e tantos outros novos aparatos da modernidade, teriam tratado de minar. $\mathrm{O}$ discurso do autor estava alinhado com as ideias de parcela da elite dominante paulistana conservadora, ligada ao meio rural, que buscava afirmação nas tradições do passado, ainda que fossem por ela idealizadas.

Em outra ocasião Guilherme de Almeida transcreve em sua coluna "Cinematógrapho" a elogiosa carta de Sílvio Romero agradecendo ao folclorista Cornélio Pires pela ocasião do lançamento de seu livro Scenas e paisagens da minha terra, publicado pela editora de Monteiro Lobato, em 1922. O artigo, veiculado no jornal $O$ Estado de S. Paulo, é representativo de um discurso que buscava no meio rural uma tradição sobre a qual fosse construída uma certa identidade nacional, uma dada brasilidade.

Sílvio Romero, agradecendo o autor [Cornélio Pires], em carta, a remessa do seu livro, disse o seguinte: Apreciei imensamente o cheste, a cor local, a graça, a espontaneidade de suas produções, que além de seu valor intrínseco, são um documento para o estudo dos brasileirismos de nossa linguagem. [...] revelando profundo conhecimento da raça, intensa ternura pelos nossos patrícios que sofrem, labutam e um brasileirismo integral sem ressaibos estranhos e sem artifícios a reçumar de cada verso, de cada frase, de cada ritmo. ${ }^{5}$

\footnotetext{
${ }^{3}$ Os discursos que procuravam valorizar certos aspectos tradicionais da cultura marcam a busca pela construção de uma identidade nacional, que excluía os negros, romantizava os indígenas e, na passagem do século XIX para o XX, incluíu as figuras do caboclo, do sertanejo e do caipira, numa visão do "homem rural pitoresco, sentimental, jocoso, favorecendo a seu respeito ideias feitas perigosas tanto do ponto de vista social quanto, sobretudo, estético". CANDIDO, Antonio. Literatura e sociedade: estudos de teoria e história literária. São Paulo: Companhia Editora Nacional, 1973, p. 111.

${ }^{4}$ ALMEIDA, Guilherme de. São João. O Estado de S. Paulo, São Paulo, 24 jun. 1927.

${ }^{5}$ Idem, Scenas e paisagens da minha terra. O Estado de S. Paulo, São Paulo, 7 jul. 1922.
} 
As vozes intérpretes das mudanças que marcaram os primeiros anos do século XX, especialmente em São Paulo e Rio de Janeiro, são plurais. Ao lado do discurso conservador e crítico ao progresso técnico e às mudanças ocorridas no crescente espaço urbano, havia outro, cujo projeto de nação ganhava fôlego e buscava consolidar-se como hegemônico, celebrando a modernidade e enaltecendo o espaço urbano como palco do progresso e da civilização, ainda que numa representação um tanto idílica da cidade como locus sem tensões nem contradições. Alguns cronistas e memorialistas atestam essa postura, que também representava a de uma parcela da elite cosmopolita. "São Paulo é a cidade mais harmoniosa do Brasil e aquella onde o homem deu mais evidente prova de sua capacidade de realização. Plana, sem a topografia e os contrastes naturaes que fazem a beleza e o deslumbramento do Rio de Janeiro, ella é, entretanto, um encanto para o viajante que a contempla. É a criação exclusiva do trabalho e da inteligência". ${ }^{6}$

No entanto, a essa postura idealizada sobre os nascentes centros urbanos contrapunha-se um cosmopolitismo repleto de contradições, cuja principal característica era a tensa convivência de opostos, marcada por um espaço ao mesmo tempo arregimentador e fragmentário, convidativo e ameaçador, numa representação ambivalente de local de origem de um caos avassalador e matriz de uma nova vitalidade emancipadora. Nesse sentido o cinema falado, representante dessa vitalidade emancipadora, foi muito além de sua vocação de divertimento das massas. Ele foi sistematicamente disputado pelos projetos de nacionalidade e de brasilidade que ocupavam a arena do espaço público.

\section{O que se fala do cinema falado: diálogos em revista}

A aceitação do cinema falado não foi unânime. Nem aqui nem em Hollywood. As matérias veiculadas nos três anos finais da década de 1920, na revista Cinearte, reproduzem a polarização da discussão entre os (poucos) entusiastas da novidade e aqueles que apontavam dificuldades em sua implementação, o que incluía adaptações técnicas, econômicas, estéticas e narrativas.

Para Jesse L. Lasky, co-fundador da Paramount Pictures, a sincronização do som às imagens em movimento comprometeriam o resultado estético e "realístico" do cinema. Segundo ele:

Os films falados modificaram por completo a arte cinematographica. E não para melhor. Um film, qualquer que elle seja, mostra a aç̧ão muito mais rapidamente do que o drama falado, e o seu maior poder reside na suggestão. Exemplo: dois homens conversam animadamente. De repente, apparece um letreiro em que um delles diz, dramaticamente: "Não posso faze-lo!". Mas se nossos artistas tivessem que falar, a nossa scena de acção ficaria muito limitada, pois elles teriam que ficar bem dentro do raio do apparelho registrador da voz, o que seria impossível em scenas exteriores. E como seria ridículo mostrar na tela uma rua movimentada com a voz dos artistas sendo os unicos sons syncronizados! Onde já se viu um automovel silencioso, ou uma

${ }^{6}$ LEÃO, Antônio Carneiro. São Paulo em 1920. Rio de Janeiro: Anuário Americano, 1920, p. 10. 
multidão muda? Taess condicóes arruinariam inteiramente o realismo a que o Cinema ja nos habituou. ${ }^{7}$

O poderoso diretor dos grandes sucessos da Paramount Pictures, Cecil B. de Mille, estava entre os que não apostavam numa mudança radical na indústria cinematográfica, com a entrada do cinema falado. Para ele "mesmo que já houvesse um invento para combinar, a perfeição, a cor, a voz e o movimento, não creio que as grandes emprezas permittiriam uma mudança radical e immediata. Destruir um systema que custou milhões de dollares seria uma loucura". ${ }^{8}$ Para Fred Niblo, que em 1925 dirigiu o sucesso de bilheteria Ben-Hur, "Os films falados nunca farão perigar o drama silencioso [...] São apenas uma novidade que desapparecerá dentro de muito pouco tempo". ${ }^{9}$ Para Samuel Goldwyn, um dos fundadores da Paramount e criador da Goldwyn, que tornou-se a Metro-Goldwyn-Mayer em 1924, "quando a grande imagem na têla começar a falar, a ilusão da realidade, em vez de aumentada, será diminuída. E por essa razão eu tenho quase a certeza de que os films falados jamais substituirão o drama silencioso" ${ }^{10}$

Por outro lado, o chefe dos estúdios da M.G.M, Irving Thalberg acreditava que "os films falados substituiriam o drama silencioso. É uma novidade que muito dignifica a indústria cinematográphica, e que, indubitavelmente, avançará muito a favor do público nos próximos anos". ${ }^{11}$ Douglas Fairbanks, estrela e co-fundador - juntamente com Mary Pickford e Charles Chaplin e D.W. Griffith - da United Artists, acreditava que "dentro dos próximos dez annos devemos esperar muitos novos aperfeiçoamentos para a arte moderna e o cinema falado pois há belleza na côr, na música, na composição e no movimento; não vejo, portanto, razões para ainda estarem separados". ${ }^{12}$

A transição do sistema Vitaphone de gravação do som em disco para o sistema óptico, onde o som era gravado diretamente na película, impôs amplas mudanças técnicas não só nas salas de exibição - que precisaram se adaptar para, eventualmente, usar os dois sistemas durante alguns anos, já que foi somente em 1938 que a Academy of Motion Picture Arts and Sciences (Ampas) normatizou o uso do sistema óptico como padrão para registro, equalização e veiculação do som sincronizado às imagens -, mas também nos sistemas de produção, o que exigiu grandes mudanças e adaptações por parte de todos os envolvidos no set de filmagem.

Os diretores, acostumados a dar instruções aos atores enquanto a cena era rodada, tiveram que encontrar novas soluções de direção do elenco, já que a gravação de som era feita em uma única pista ao mesmo tempo em que a imagem era gravada. Os atores, por sua vez, precisaram abandonar o estilo de interpretação calcado na pantomima e passaram a buscar outras formas de atuação, considerando suas vozes e entonações como partes da narrativa fílmica.

\footnotetext{
${ }^{7}$ LASKY, Jesse L. apud Os films devem falar? Cinearte, anno II, n. 73, Rio de Janeiro, 20 jul. 1927, p. 13.

${ }^{8}$ DE MILLE, Cecil B. apud Os films devem falar? Cinearte, anno II, n. 73, op. cit., p. 13.

${ }^{9}$ NIBLO, Fred apud Os films devem falar? Cinearte, anno II, n. 73, op. cit., p. 34.

${ }^{10}$ GOLDWYN, Samuel apud Os films devem falar? Cinearte, anno II, n. 73, op. cit., p. 34.

11 THALBERG, Irving apud Os films devem falar? Cinearte, anno II, n. 73, op. cit., p. 12.

12 FAIRBANKS, Douglas apud Os films devem falar? Cinearte, anno II, n. 73, op. cit., p. 34.
} 
Em Hollywood, a presença de estrelas e diretores estrangeiros nos quadros dos grandes estúdios também foi motivo de algumas complicações extras, já que muitos deles mal falavam inglês. Esse foi o caso do diretor sueco Mauritz Stiller, que desistiu da direção do filme The temptress (1926), entregando-o à Fred Niblo, "não por se sentir doente, como a princípio se disse, mas por ter visto a impossibilidade de se fazer comprehender pelos artistas, exceptuando, naturalmente, a linda Greta Garbo, sua patrícia". ${ }^{13}$

Com o cinema falado, a língua passou a ser uma questão importante na constituição do star system dos grandes estúdios, que frequentemente traziam atrizes estrangeiras para compor seu casting. O caso de Greta Garbo é emblemático. Como várias artistas estrangeiras importadas por Hollywood, Greta "não é lá muito afiada em inglez. Na verdade ella conseguiu para seu gosto um pequeno vocabulario de slang, que a ajuda em algumas occasiões." Como, indaga ella preoccupada, poderei eu aprender inglez?"14 Já entre as estrelas estadunidenses, havia as que apresentavam problemas de dicção, sotaques e/ou acentos fonéticos que remetiam suas ascendências à regiões dos Estados Unidos consideradas por Hollywood, caipiras e atrasadas, o que poderia comprometer fortemente suas imagens de estrelas modernas, urbanas e bem sucedidas que os estúdios buscavam construir e vender ao grande público, consonante com a ideia de uma América moderna e livre.

No Brasil, as opiniões dos editores de periódicos especializados na crítica cinematográfica, assim como a de leitores que colaboravam nas colunas dedicadas ao cinema, seguem a mesma polarização, com uma importante diferença: aqui, para além da questão econômica em relação à adaptação das salas de cinema ao filme falado e do problema técnico da qualidade do som, havia também o debate sobre o nacionalismo e a construção de uma identidade nacional que passava necessariamente pelo problema da língua.

Inicialmente a preocupação do mercado exibidor girou em torno dos investimentos necessários para aparelhar as salas de cinema com a novidade. Com a despesa prevista para o aluguel do equipamento, a perspectiva era de que a novidade demoraria a chegar nas cidades menores, com menos recursos.

Provavelmente as primeiras perguntas que os exhibidores farão sobe o Vitaphone, serão estas: "Quanto custará?", "Como conseguir um aparelho completo"? [...]. O que custará tal aparelho é problemático. Em todo caso, porém, já se diz em New York que uma instalação completa custará menos do que um órgão. O Vitaphone náo sera vendido e sim alugado. Em todas as cidades em que o serviço estiver istallado, todas as vezes que for exhibido um film que tenha sido filmado por esse processo, isto é, que tenha musica ou dialogo fornecido pelo Vitaphone, o exhibidor que tenha em seu Cinema a invenção, poderá mediante preço relativamente pequeno, proporcionar à sua plateia as delicias do cinema falado. Provavelmente passará muito tempo antes que o Vitaphone seja uma realidade nos Cinemas das pequenas cidades e aldeias. Por enquanto, ficara na grades capitães. ${ }^{15}$

\footnotetext{
${ }^{13}$ STILLER, Mauritz apud Cinearte, anno I, n. 8, Rio de Janeiro, 1926, p. 27.

${ }^{14}$ Cinearte, anno I, n. 12, Rio de Janeiro, 1926, p. 6.

${ }^{15}$ Cinearte, anno I, n. 3, Rio de Janeiro, 1926, p. 3.
} 
As primeiras sessões do cinema falado amplamente noticiadas pela mídia impressa, ocorreram nas cidades de São Paulo e Rio de Janeiro, respectivamente no Cine Paramount em 13 de abril de 1929 e no Rio de Janeiro em 20 de junho do mesmo ano. Entretanto, a despeito das exibições crescerem nessas capitais, o investimento no cinema sonoro não atingiu da mesma maneira as demais regiões do país. Segundo Freire ${ }^{16}$, para os exibidores do interior, além dos altos custos das instalações (projetores, retificadores, alto-falantes etc), o elevado preço de aluguel das cópias dos talkies cobrado pelas distribuidoras transformava-se em um problema. "As grandes casas de exibição geram enormes despesas com o aparelhamento, as menores, à míngua de recursos, buscaram derivativos nos aparelhos sincronizados [por discos]; os mais modestos ainda sujeitaram-se a programar filmes velhos ou então as versões silenciosas dos filmes sonoros ainda piores do que aqueles". ${ }^{17}$

Além das questões econômicas, os problemas técnicos relacionados ao cinema falado foram pauta da imprensa especializada durante um longo período. As manifestações dos leitores nestes periódicos indicam a precariedade da novidade, o que pode ser atestado por declarações como esta, endereçada ao operador da sessão à qual autor esteve presente, publicada na "Coluna do Leitor" da Cinearte, dia 25 de junho de 1929:

Acabo de assistir no Palacio Theatro ao Cinema Falado.

A falar com franqueza, Operador, a impressão que tive foi a peor possivel, e nem sei mesmo como há pessoas que achem que "aquillo" é um assombro. Para mim o theatro nada vale, tenho verdadeiro horror a elle, mas Cinema falado é dez vezes peor. Quem está na sala de espera e assiste de longe (como no Palacio) a projecção de um film falado, tem a impressão de um Cinema sem orchestra com um alto falante desses que ouve-se a cada momento pelas ruas. O ruído que faz o microfone, mormente quando passa por emenda, é simplesmente detestável. Nesse film então há scenas que chegam a tornar-se ridículas. A ultima dellas, tomada no interior de um automóvel em plena Broadway, não se ouve um único ruído, tão característico das artérias movimentadas, apenas a voz dos interpretes. ${ }^{18}$

Passados quase dez anos da chegada do cinema falado nas capitais de São Paulo e Rio de Janeiro, os problemas técnicos persistiam, conforme artigos veiculados na revista Cine Magazine, que por ocasião da estreia do filme dublado Branca de Neve e os sete anões, em 1938, publicou um texto do crítico José Sanz, que se perguntava: "por que é tão ruim o som dos films nacionais?". Rafael de Luna Freire, nos desafia a pensar se a resposta para o problema estaria nos filmes ou nas salas de cinema. Em campanha permanente pela melhoria das salas de exibição, o periódico publicou o artigo "Melhores aparelhos para maior frequência":

O espectador, num cinema, às vezes culpa a sincronização de um filme, esquecendo, geralmente, que o defeito provém da péssima aparelhagem sonora [...] Os cinemas equipados com aparelhagem sonora, muitos datam de oito e dez anos atrás, e em grande

\footnotetext{
${ }^{16}$ Cf. FREIRE, Rafael de Luna. A conversão para o cinema sonoro no Brasil e seu mercado exibidor na década de 1930. Significação: Revista de Cultura Audiovisual, v. 40, n. 40, São Paulo, 2013.

${ }_{17}$ Cinearte, anno VI, v. 6, n. 276, Rio de Janeiro, 10 jun. 1931, apud FREIRE, Rafael de Luna, op. cit., p. 3.

${ }^{18}$ Cinearte, anno IV, n. 176, Rio de Janeiro, 10 jul. 1929, s./p.
} 
maioria, encontramos os chamados "tapiaphones", e outros que, sendo reputadas marcas, precisam, podem e devem ser renovados a bem do conforto público, e da satisfação da bilheteria do exibidor. ${ }^{19}$

Em anúncio das novas instalações de projetores e de um moderno sistema sonoro no Cine Rex, no Rio de Janeiro, uma nota na Cinearte, de 1935, dava conta de que até aquele momento, as várias tentativas de melhorias técnicas no sistema de som não passaram de uma grande "tapeação": "Annunciaram agora uma nova installação de projectores e parte sonora com systema Wide Range para substituir o aparellhamento de $2^{a}$ mão que lá existia. Mas esperemos para ver se desta vez será verdade. Não há muito tempo, o Cinema annunciou a mesma cousa, com grande alarde e afinal não passava mesmo de uma grande tapeação". ${ }^{20}$

Em carta à revista A Cena Muda intitulada, "Se em todos os filmes fossem feitas doublagem", o leitor mineiro, após quase treze anos da chegada do cinema falado, afirmava que "em todo o Estado de Minas Gerais pouco mais de meia dúzia de cinemas seriam capazes de passar filmes dublados "de modo que o publico compreendesse o que dizem os personagens". E continua, dizendo que "nos demais cinema que ele conhecia não seria possível exibir adequadamente filmes dublados, apesar de eles serem cinemas de certa classe, cujo único defeito é a aparelhagem defeituosa". ${ }^{21}$ Apesar do barateamento e da crescente oferta dos equipamentos nacionais para atender os pequenos exibidores, a conversão do circuito exibidor nacional para o cinema sonoro demorou a acontecer.

\section{O que se fala no cinema falado: questões sobre a construção do sentido de nação}

Extrapolando para o cinema a afirmação de Rancière ${ }^{22}$ de que a escrita é uma prática política - já que o ato de escrever é uma maneira de ocupar o sensível e de dar sentido a essa ocupação -, e considerando o filme como uma escrita, um discurso capaz de mobilizar opiniões, construir e desconstruir efeitos de verdade, deve-se ponderar que sua atuação está no cerne do exercício do poder, desempenhando importante papel político no processo de construção e disseminação de um discurso que visava construir uma brasilidade e criar um sentido de nação.

O potencial didático do cinema falado como divulgador de conhecimentos, hábitos, costumes e imagens, construtor e promotor de uma unidade (imaginada) de país, juntamente com a ideia de que ele era um "artifício, uma arma moderna, portadora e transmissora da modernidade" ${ }^{\prime 23}$, era abertamente veiculada por parte dos intelectuais, cineastas e jornalistas que escreviam nas páginas da emblemática revista Cinearte

\footnotetext{
${ }^{19}$ Cine Magazine, v. 6, n. 65, set. 1938, apud FREIRE, Rafael de Luna. "Versão brasileira" - Contribuições para uma história da dublagem cinematográfica no Brasil nas décadas de 1930 e 1940. C-Legenda, Niterói, 2011, p. 4.

${ }^{20}$ Cinearte, n. 417, Rio de Janeiro, 1935, p. 27.

${ }^{21}$ A Cena Muda, v. 21, n. 1092, 24 fev. 1942, apud FREIRE, Rafael de Luna, op. cit., p. 13.

${ }^{22}$ Cf. RANCIÈRE, Jacques. Políticas da escrita. São Paulo: Editora 34, 1995.

${ }^{23}$ SCHVARZMAN, Sheila, Humberto Mauro e as imagens do Brasil. São Paulo: Editora Unesp, 2004, p.18.
} 
O filme sonoro veio abrir novos horizontes à cinematographia sob um ponto de vista que até aqui, que saibamos, não foi ainda encarado: o cinema educativo, o film destinado a instruir, não somente a divertir. De facto, para o film educativo desaparecem as dificuldades que por muito tempo ainda embaraçarão o film commum. O cinema conta ainda muitos adversários que nelle só vêm o lado máo; entretando se encararmos exclusivamente essa face - o seu aproveitamento como divulgador de conhecimentos, se por momentos reflectimos nas possibilidades imensas que elle vae cada dia offerecendo para a tarefa da educação popular teremos de confessar que raras invenções humanas poderão ser tão úteis à humanidade. ${ }^{24}$

Antes mesmo da chegada do cinema falado, parte da imprensa escrita já discutia sobre seu potencial disseminador de ideia e valores. Entre os que destacavam como positiva a função pedagógica do cinema estava Monteiro Lobato, cujo personagem mais famoso, o Jeca Tatu, encarnava um caipira rural de forma caricatural, com todas as características que o autor considerava negativas. Segundo ele, o cinema "é uma escola' para o povo brasileiro: nela, Jeca Tatu aprenderá tudo, comportamentos éticos, hábitos e posturas, para tornar-se um homem com $\mathrm{H}$ maiúsculo em todas as situações da vida". ${ }^{25}$

Contudo, na mesma medida que apresenta potencial de ampla divulgação de gostos e costumes considerados adequados para a conformação de uma certa brasilidade, o cinema também poderia servir a propósito oposto, ao introduzir "maos hábitos em nossa sociedade". Nesse sentido, a Revista Feminina ${ }^{26}$ - fundada em 1914 por Virgilina Salles de Souza e voltada para o público feminino das elites letradas constituída pelas esposas, filhas e netas da oligarquia rural urbanizada e de prósperos homens de negócios enriquecidos pelo comércio urbano e pelas exportações -, foi uma das mais influentes vozes do que se pode chamar de modernidade conservadora. Em suas páginas, em diferentes ocasiões, o cinema foi objeto de crítica por substituir nomes de políticos de nossa cultura nacional por estrelas do star system hollywoodiano.

\begin{abstract}
O cinema
A expressão de uma sociedade embryonaria, são os nossos cinemas actuaes. Expoente máximo de tudo quanto é pernicioso, o cinema, até o presente momento, só visou introduzir os máos hábitos na nossa sociedade. [...] As criancinhas de hoje, logo cedo contaminam-se pela maldade da cinematografia moderna, que as deixa inteiramente compenetradas em um William Farnum ou em uma Pearl Wite, a um nome representativo da nossa História. No cérebro desses entesinhos tão mal encaminhados, por que se não introduzir um nome valoroso de Silva Jardim ou de Floriano Peixoto?27
\end{abstract}

\footnotetext{
${ }^{24}$ Cinearte, anno IV, n. 176, Rio de Janeiro, 10 jul. 1929, s./p.

${ }^{25}$ LOBATO, Monteiro. A onda verde. São Paulo: Monteiro Lobato \& Cia, 1921 apud FABRIS, Annateresa. O futurismo paulista: hipóteses para o estudo da chegada da vanguarda no Brasil. São Paulo: Perspectiva, 1994, p. 193.

${ }^{26}$ Entre os inúmero colaboradores da Revista Feminina encontram-se o escritor Cláudio de Souza, que assinava os editoriais da revista com pseudônimo feminino de Ana Rita Malheiros, Coelho Neto, Antônio Austregésilo, Menotti del Picchia e as escritoras Júlia Lopes de Almeida e Chrysanthème. Destinava-se sobretudo ao público feminino, com seções sobre comportamento da mulher, relacionamento conjugal, etiqueta, culinária, moda, trabalhos manuais. Publicava contos, charges, artigos de assuntos gerais e muita publicidade. Vendida em todo o Brasil, alcançou uma tiragem de 25 mil exemplares por mês, o que a colocava entre as revistas de maior circulação do período.

${ }^{27}$ O cinema. Revista Feminina, ano VIII, n. 80, São Paulo, 1921, p. 1.
} 
Diante de tal constatação a autora do texto prossegue em seus argumentos, posicionando-se a favor da transformação do cinema em "um paradigma de instrucção e educação". Para isso sugere que esse 'antro de perdição' seja transformado em um instrumento difusor de "luzes de bons e salutares ensinamentos". E segue alertando para o perigo que representa os "films cinematographicos" à criança alfabetizada, pois esta é capaz de absorver mais os "subsídios falsos" do cinema que "deformam" o caráter infantil. Ensina, por meio de um discurso higienista, que assim como "os nossos músculos precisam de gymnastica, nosso espírito precisa de cultura". Clama pelo controle urgente dos films e convoca a população a mobilizar-se em uma "campanha em prol dos bons costumes". E termina, conclamando "Desenvolvamos os músculos sem contudo descuidarmos do espírito. [...] Ensinemos altivez ás creancinhas, incutindo- lhes sentimentos piedosos. Dignifiquemos o Brasil!" ${ }^{28}$

Ao debate do cinema falado como divulgador de um projeto de brasilidade, vitrine de uma nacionalidade coesa, harmônica e moderna, juntou-se a questão sobre seu estatuto artístico e estético. O cinema falado poderia ser considerado arte ou esse status seria conferido somente ao cinema silencioso? Ao analisarmos mais detidamente os artigos que traziam essa problemática, vemos que essa era uma falsa questão. O que estava em jogo nesse debate era menos o fato o cinema ser falante (ou não) e mais o tipo de conteúdo que ele veiculava e em que língua ele fazia isso.

Em carta enviada à sessão "Página dos Leitores", da Revista Cinearte intitulada "Sobre a estreia do cinema falado", um leitor que se apresentava como um "antigo e verdadeiro fan", anunciava que

O som não poderá preencher a verdadeira arte do cinema", ao contrário, ele concorreria para "transformar completamente a significação do cinema, que deixa de ser a arte do silêncio para se tornar a arte da Barafunda, ou uma nova espécie de praga de altos falantes berrantes. Creio que os verdadeiros "fans" não terão duvida em reconhecer a grandiosidade do invento, mas não é menos certo que o cinema sonoro é uma vaidade americana, sem vantagem nenhuma para os fins do Cinema-Arte. ${ }^{29}$

O entendimento de que o cinema sonoro era uma "vaidade americana" e que o filmes silenciosos seriam a expressão de uma "verdadeira arte", deixa claro que o cinema falado era uma ameaça não à "arte do silêncio" mas sim ao cinema nacional. O cinema dialogado, como também era chamado, chega mesmo a ser considerado "retrógrado" pelo autor, já que "a riqueza de detalhes e de expressões substitue [...] a dialogação". Continuando, o leitor não deixa dúvida de que sua defesa não se fazia em favor do cinema mudo contra o dialogado, mas sim, do cinema brasileiro contra o "sonoro americano ou de qualquer outro paiz de origem":

Disseminado no Brasil o cinema sonoro americano, ou de qualquer outro paiz de origem, elle só poderá permanecer no limitado numero das nossas melhores casas, pois podemos afirmar, é relativamente pouco numerosa a quantidade de indivíduos que poderão comprehender a dialogação. O cinema falado é entre nós apenas uma innovação,

\footnotetext{
${ }^{28}$ Idem.

${ }^{29}$ Cinearte, anno IV, n. 176, Rio de Janeiro, 10 jul. 1929, p. 19.
} 
mas está fadado ao desprezo. É sempre melhor o Cinema Brasileiro, que já possue uma constelação de valor. Vamos vêr Braza dormida e Barro humano, pois o film sonoro não tem futuro para nós. ${ }^{30}$

O final da carta deixa explícito o tom nacionalista de sua crítica, quando afirma que é sempre melhor o cinema brasileiro, já que possui "uma constelação de valor". Nesse sentido, os filmes Brasa dormida (1928) dirigido por Humberto Mauro e Barro humano (1929), dirigido por Adhemar Gonzaga, foram anunciados como referências para as novas produções nacionais, cuja função deveria ser a de mostrar alguns aspectos do Brasil, para o Brasil: “O Brasil é tão grande, tão variado, os costumes, tão diferentes os aspectos da vida, quer nas cidades, quer nos campos [...] A função patriótica do film genuinamente nacional seria pôr esses aspectos da vida provinciana ao alcance de todo brasileiro". ${ }^{31}$

Para isso, continua o leitor, a indústria brasileira de cinema deverá "desviar-se na escolha dos seus assumptos desses eternamente batidos e reprisados themas que se desenvolvem apenas nas cidades", como por exemplo Paris, Londres e Nova Iorque, para produzir algo para "efeito da propaganda patriótica". ${ }^{32}$ Em outro espaço da revista, um correspondente de São Paulo mantêm o tom nacionalista e ufanista em grafia maiúscula, quando escreve por ocasião da estreia de Barro humano, mostrando-se ansioso em relação à recepção do público paulista. “Eu tenho plena e absoluta convicção de que esse mesmo publico apparentemente frio [o paulista], saberá, quando oportuno, dar o seu applauso incondicional e confortador à obra [Barro humano], feito com os sacrifícios innumeros de moços BRASILEIROS que se preoccupam, seriamente, com cousinhas serias que elevem um nome glorioso e lindo que todos temos no coração: BRASIL!". ${ }^{33}$

Em ocasião anterior, em matéria escrita para divulgar o concurso Medalhão Cinearte, que premiou o filme Thesouro perdido (1927) de Humberto Mauro como melhor filme nacional, Pedro Lima, um dos editores da revista, deixa claro que o componente regionalista foi o grande vencedor: "É bem caracteristicamente brasileiro: é "branco" pois não tem cena nenhuma imoral, [...] Thesouro perdido é superior em conjunto como dissemos e tem mais qualidade. Uma delas é o tratamento do assunto sob o ponto de vista brasileiro. Thesouro perdido apresenta o verdadeiro interior do nosso país". ${ }^{34}$

Segundo a historiadora Ana Paula Spini, para compreender o que se considerava um filme "branco", "faz- se necessário reportar à campanha maciça da revista contra os filmes naturais e as imagens, consideradas indesejáveis, veiculadas por eles, como indígenas, cangaceiros, negros em danças exóticas. Era preciso mostrar um país civilizado, branco, moderno". ${ }^{35} \mathrm{Em}$ ou-

\footnotetext{
${ }^{30}$ Idem.

31 Cinearte, n. 173, Rio de Janeiro, 19 jun. 1929, p. 3, apud LUCAS, Tais Campelo. Cinearte: o cinema brasileiro em revista (1926-1942). Dissertação (Mestrado em História) - UFF, Niterói, 2005, p.129.

32 Idem.

33 Cinearte, anno IV, n. 176, Rio de Janeiro, 10 jul. 1929, p. 8.

34 O melhor filme brasileiro de 1927: o Thesouro perdido, da Phebo Brasil Film de Cataguazes, ganha o Medalhão de Cinearte. Cinearte, 25 abr. 1928, apud SPINI, Ana Paula. Cordis: História, Cinema e Política, n. 16, São Paulo, jan.-jun. 2016, p. 15.

${ }^{35}$ Idem.
} 
tra ocasião, Pedro Lima elogia a "nacionalidade" das cenas do filme, porque mostram o que "é nosso": "São nossos todos os ambientes, os typos, os usos, os costumes todos, a excepção daquella scena com o taverneiro, quando ergue o braço à americana." [...] Tambem a arma feita de cano de guarda-chuva é um uso do sertão, como características são as locações que apresentam num espetáculo admirável do nosso desenvolvimento agrário". ${ }^{36}$

A proposta de construção de um mito fundador que fornecesse elementos a determinadas representações da realidade, fundada por uma política cultural é perceptível em Cinearte. Como afirma Sheila Schwarzman, "as escolhas editoriais da revista, as fotografias e os anúncios publicados revelam, o momento em que se aspira à união entre imagem cinematográfica e identidade nacional, no qual ainda aceitava-se os princípios da eugenia para explicação da civilização" ${ }^{37}$ Porém, como ela bem nos adverte, não se deve atribuir exclusivamente ao grupo de críticos da revista essa preocupação. Ao contrário, "Cinearte era um entre vários focos onde a questão se colocava, catalizando para a imagem cinematográfica o conflituoso embate pela definição de uma identidade nacional". 38

A questão da construção da identidade nacional estava marcada pela disputa de pelo menos dois projetos de brasilidade: um ligado à exaltação do cosmopolitismo, do urbano, das novas tecnologias, da indústria e do desenvolvimento material, e outra ligada à invenção de uma tradição que combinava algumas características do regional, do campo, do sertão, do que era considerado como puro, ingênuo, ao mesmo tempo portador de sabedoria.

Entretanto, é importante lembrar que essa dicotomia urbano-rural, centro-interior, nacional-estrangeiro era apenas aparente, já que nem os discursos ligados à exaltação de um Brasil moderno e civilizado apresentavam uma unidade de entendimento em relação aos elementos que deveriam compor a "civilidade", nem os adeptos do regionalismo encontravam unidade na escolha dos elementos regionais para a composição do "espírito nacional".

Assim, ao buscarmos responder à pergunta-provocação "sobre o que falava o cinema falado?", teremos como resposta, ao invés de um uníssono harmônico, falas dissonantes que disputavam um sentido para a nação, aportadas em aspectos que tocavam ora nos regionalismos, ora em certas "tradições" (inventadas), ora em aspectos rurais, ora nas novidades urbanas, compondo diálogos que suscitavam diferentes interpretações acerca da modernidade e da própria brasilidade.

Artigo recebido em 26 de setembro de 2020. Aprovado em 10 de outubro de 2020.

\footnotetext{
${ }^{36}$ LIMA, Pedro. A propósito de Thesouro perdido e sua exibição. Cinearte, Rio de Janeiro, 16 mar. 1927, s./p.

${ }^{37}$ SCHVARZMAN, Sheila, op. cit., p. 35.

${ }^{38}$ Idem, ibidem, p. 39.
} 